\title{
LOS OTROS ARRIEROS DE LOS VALLES, LA PUNA Y EL DESIERTO DE ATACAMA
}

\author{
THE OTHER MULETEERS TRADERS OF THE VALLEYS, \\ THE HIGHLANDS AND THE ATACAMA DESERT
}

\author{
Raúl Molina Otárola ${ }^{1}$
}

\begin{abstract}
La arriería ha sido una actividad relevante para las relaciones entre la región del noroeste argentino y el desierto de Atacama, ella ha tenido un importante rol en el abastecimiento y articulación de estos territorios transfronterizos. Esta arriería tiene dos rostros, uno es el hacendal, dedicado preferentemente al traslado de ganado en pie, para el abastecimiento de carne hacia los centros mineros y salitreros, cuyo tráfico perduró hasta mediados del siglo XX y fue registrado en las estadísticas de los estados nacionales. El otro rostro, es aquel realizado por familias de la puna y el desierto de Atacama, las que transportando sus propios animales y bienes para el intercambio articularon en ambos sentidos el territorio transfronterizo argentino-chileno, actividad sustentada en las relaciones sociales a distancia que pervivieron hasta reciente época, y se desarrollaron evitando los controles de los estados nacionales. A diferencia de la arriería hacendal, donde los arrieros son contratados para llevar remesas de ganado adquiridos por empresas, la otra arriería se caracteriza por el intercambio y el trueque, por tanto, se trata de otros arrieros que elaboraron sus propios viajes y diseñaron particulares estrategias de intercambio, sustentadas en redes sociales. Para comprender su movilidad y actividad transcordillerana, este artículo analiza las relaciones ocurridas durante el siglo XX y los inicios del siglo XXI entre la puna de Catamarca, el valle de Fiambalá, el salar de Atacama y la cordillera de Copiapó.
\end{abstract}

Palabras claves: arriería, articulación transfronteriza, viajes de intercambio, desierto y puna de Atacama.

\begin{abstract}
The "arriería" or mule-trade transport has been a relevant activity for the relationships between the Argentinean Northwestern region and the Atacama Desert, playing a key role in the flow of supplies and communication between these two borderland territories. This "arriería" has two aspects: one is the "hacendal" dedicated mainly to cattle driving to supply meat to the mining centers and to the Pampa. This activity lasted until the middle of the 20th Century and was recorded in respective national statistical registries. In studies of this type of "arriería", muleteers are not mentioned; most of the time they are cited as natives or indigenous people. The second aspect of "arriería" is performed by families of the highlands and the desert, who haul their own cattle and goods to establish two-way connections through the borderland territory. This activity is accomplished outside any government or state control and is maintained by long-distance social relationships. Contrary to the "arriería hacendal"-studied by virtue of secondary information-, to understand this other type of "arriería" we need to focus on these "other" muleteer traders. From this point of view our work conveys important aspects for understanding this trans-borderland territory exchange during the XX and the beginning of the XXI Centuries.

Key words: Mule-trade transports ("arriería"), trans-borderland articulation, exchange, transhumance, Atacamenian
\end{abstract} Desert and Puna.

La arriería entre el noroeste argentino (NOA) y el desierto de Atacama ha sido analizada para fines del siglo XIX y hasta mediados del siglo XX como una actividad empresarial de abastecimiento de carne de vacuno en pie o hacienda, destinada a satisfacer la demanda de la población de los enclaves mineros y salitreros, de pueblos y ciudades de las regiones de Antofagasta y Tarapacá. Importantes trabajos han dado luz sobre estas articulaciones transfronterizas asociadas al ciclo salitrero, que se extiende entre los años 1880 y 1930 (Conti 2003, 2006). En estos estudios las fuentes más utilizadas son las estadísticas de las remesas de ganado obtenidas de los registros aduaneros del Estado, aunque en muchos casos éstas se consideran parciales, debido a la existencia del transporte ilegal de ganado (Aranda 1969; Conti 2003) ${ }^{1}$.

La arriería hacendal, desde una perspectiva estructural de la economía, se inserta en el sector transporte de bienes y productos de las economías formales de exportación de ganado. En este contexto, los arrieros son trabajadores asalariados de los hacendados o prestan servicios de transporte. Se trata de una arriería empresarial y/o de "arrieros

1 Programa Doctorado, Universidad de Tarapacá-Universidad Católica del Norte. Centro de Investigaciones del Hombre en el Desierto, CIHDE.raul.otarola@gmail.com 
profesionales" que dan un servicio especializado, cuyo perfil sociocultural está poco estudiado para tiempos republicanos ${ }^{2}$, aunque en su mayoría se les caracteriza como arrieros de condición indígena (Conti 2003), y a algunos, en el siglo XIX, se les identifica con el etnónimo atacameño (p.ej., Phillipi 1860; Von Tschudi 1966). A estos arrieros se les localiza en poblados asociados a las rutas tradicionales de tráfico del ganado, como San Pedro de Atacama, el valle Calchaquí -entre ellos, Payogasta, Molinos y Cachi- y, en Salta, se nombra a la Quebrada del Toro, así como a “... Pampa Llana, Aporoma, Hualfin de Salta... (como los)... los pueblitos que tenían el monopolio del arreo de animales que se llevaban a Chile"3. Estas localidades proporcionaban mano de obra, pastaje y servicios asociados al tráfico arriero ${ }^{4}$.

La arriería hacendal, que perdura hasta la mitad del siglo XX, no ha sido el único tipo de movilidad y articulación transfronteriza, también existe la arriería de caravanas de llamas de la provincia de Jujuy, estudiada entre otros por Cipolletti (1984) y Göbel (1998). Por otro lado, en la geografía meridional de la puna y del desierto de Atacama, al sur de las rutas ganaderas tradicionales, se desarrolló una arriería indígena, que consideró la articulación e intercambio transfronterizo entre el valle de Fiambalá, la puna de meridional de Atacama-Antofagasta de la Sierra y salar de Antofalla- en Argentina, con la quebrada de Paipote y Potrerillos, en la cordillera de Copiapó, y los poblados de Peine y Socaire, en el desierto de Atacama, Chile (Figura 1). Esta desconocida arriería indígena ha sido posible relevarla en estos poblados a través de la recuperación de testimonios de quienes la conocieron o practicaron. Dichos relatos abarcan desde las primeras décadas de 1900 hasta los primeros años del siglo XXI, lo que demuestra que durante el siglo XX coexistió y superó en el tiempo a la arriería hacendal.

Estos otros arrieros integraban familias que habitaban los poblados indígenas de la puna y el desierto de Atacama y que por su posición geográfica mantenían cierta lejanía de los centros urbanos y se caracterizaban por su aislamiento. Sin embargo, entre ellos había cierta vecindad, aunque separados la mayoría de las veces por largas distancias, accidentes geográficos y líneas fronterizas, que eran superadas a lomo de mula, en viajes de uno o varios días de duración. Los habitantes de estos poblados dedicados a actividades agropecuarias, de caza y recolección, minería eventual y producción textil movilizaban una parte de su producción para el intercambio por productos complementarios y manufacturados, estos últimos adquiridos principalmente en la vertiente chilena, además de incorporarse a estos circuitos las hojas de coca provenientes de Bolivia. Estos intercambios transfronterizos complementaban de cierta forma la producción de los pisos ecológicos de puna, valle y desierto, y activaban sus economías locales.

Los otros arrieros, a diferencia de los arrieros de ganado hacendal, generalmente llevaban animales de su propiedad o de miembros de la misma localidad, transportando burros, mulas y ovejas y, ocasionalmente, algunos ejemplares de vacuno. Las mulas y burros eran cargados de productos agrícolas y textiles, propios o adquiridos a conveniente precio, llevados para el intercambio o 'cambalache', con los que se obtenían recursos complementarios para las economías familiares (Molina 2007). La articulación del espacio puna-valle-desierto la hacían en ambos sentidos y en distintas temporadas del año. La dirección de la arriería dependió de las necesidades de abastecimiento de productos complementarios, de la conveniencia del intercambio, de los valores equivalentes que los productos y animales traficados adquirían en una y otra vertiente de la cordillera de los Andes.

En sus viajes no existían los trámites migratorios, los permisos y registros de entrada y salida de los países, visas de estadía, ni pasaportes o cédulas de identidad que se deben exhibir para atravesar la frontera. Los otros arrieros evitan entonces los pasos oficiales, el contacto con la policía fronteriza, la fiscalización de las Aduanas y no registran sus arreos y mercancías de acuerdo a los códigos sanitarios de cada país. Algunos antecedentes documentales de los otros arrieros podrían encontrarse consultando partes policiales y procesos judiciales por contrabando e ingreso ilegal, seguidos contra arrieros interceptados con sus cargas, tanto en Argentina como en Chile ${ }^{5}$. Se trata entonces de arrieros que constituyen parte de una realidad andina que "... se desenvuelve fuera del alcance de la percepción administrativa, y por tanto, fuera de este tipo de documentación" (Guerrero y Platt 2000:96).

Para comprender este otro mundo de la arriería, donde no existen estadísticas y aproximaciones cuantitativas o cualitativas, es preciso introducirse en el análisis etnográfico y reflexionar sobre los datos que aporta el trabajo de campo (Guber 2005; Hammersley y Atkinson 1994), interrogando la 


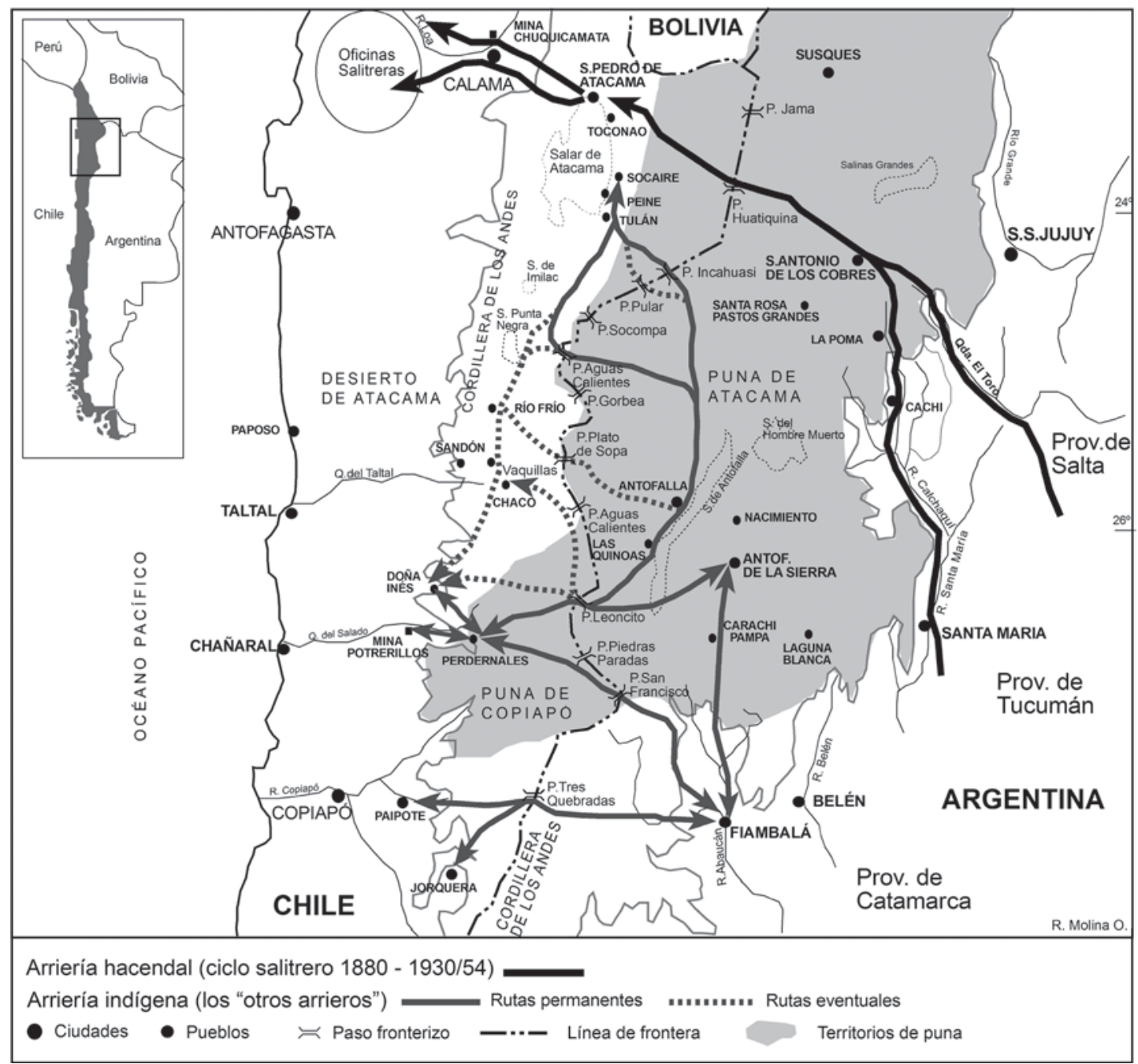

Figura 1. Mapa de rutas de arriería e intercambio transfronterizo entre la Puna y el Desierto de Atacama, durante el siglo XX. Map of the mule-trade transport routes and the trans-borderland exchange between the Puna and Atacama Desert during the $X X^{\text {th }}$ Century.

información para alcanzar una mejor comprensión de los procesos y de las características de los otros arrieros. Adentrarse en el mundo de la otra arriería requiere situarse en el tiempo del relator, en la perspectiva del arriero, del que relata la experiencia vivida, del actor que diseña en su memoria las imágenes del viaje de intercambio, viaje que debió considerar en su planificación evitar los controles policiales fronterizos, escoger la ruta adecuada, calcular el tiempo de desplazamiento y considerar los peligros naturales del camino a fin de minimizar los riesgos y peligros para llegar a destino con sus animales y carga ${ }^{6}$.

Estos arrieros, en su viaje y al momento de cruzar la frontera chileno-argentina, constituida en Atacama a fines del siglo XIX, ejercieron una discreta "desobediencia" a las normas de los estados nacionales que impedían y perseguían este tipo de tráfico, la que quizás se expresó en un primer momento como forma de obviar las demarcaciones arbitrarias de límites, y posteriormente, lo fue evadiendo los controles del Estado y la mayor vigilancia de las fronteras. En esta lógica, siguiendo una idea de Bhabha (2000), esta arriería es una manera de trastocar el control del Estado, por la vía de la discreción. Es también una acción transgresora de límites fronterizos y normas legales impuestas, cuyo sentido se puede buscar en estrategias tradicionales de complementación de pisos ecológicos e intercambio de productos, en la articulación social y económica 
preexistentes a las fronteras internacionales, y en la constante reproducción de los lazos sociales, todos ellos, además, parte de prácticas de derecho consuetudinario.

\section{Arrieros, Arrierías y Fronteras Nacionales}

Para apreciar la aparición histórica de los otros arrieros es necesario abordar la existencia de tempranas relaciones de intercambio y movilidad entre los valles y la puna del NOA con el desierto de Atacama, cuya huella de interacción tiene data precolombina (Núñez 1992; Tarragó 1984). Pero la arriería en particular se inaugura en la época colonial, transportando productos, bienes y ganado desde el desierto y la puna de Atacama hacia distintos puntos de la región, en especial hacia Potosí (Sayago 1997[1874]; Santamaría 1996; Sanhueza 1991). Esta movilidad permitió establecer contactos y articulaciones económicas de larga distancia, algunas de las cuales pudieron estar respaldadas en relaciones de parentesco, debido a la interdigitación con que aparece la población indígena de la puna y el desierto de Atacama durante el periodo colonial (sensu Martínez 1998).

Las articulaciones y conexiones territoriales posiblemente se vieron reforzadas hacia fines del siglo XVII, cuando los territorios de la puna atacameña y de los valles santamarianos del NOA (Fiambalá y Calchaquí) son colonizados con tributarios provenientes de los ayllus de San Pedro de Atacama (Lorandi 1988; De la Orden y Parodi 2005; Rodríguez 2004), a los que se suman indígenas trasladados de otras zonas del área circumpuneña. Es posible que estos tributarios se involucraran tempranamente en la arriería colonial, y que luego mantuvieran vigente esta actividad hasta el siglo XIX, cuando se les encontraba arreando ganado mular a Bolivia y ganado vacuno a Chile, principalmente a las minas de Copiapó y a las incipientes salitreras de Tarapacá, en Perú (Lera 2007; Meister et al. 1963).

La vinculación de los atacameños con la puna, los valles del NOA y el desierto de Atacama, al parecer se mantuvo presente a través de los lazos familiares y políticos con las autoridades cacicales de los lugares de origen y por los lazos económicos complementarios, que se observan hasta fines del periodo colonial (Castro et al. 2002). También las vinculaciones de los atacameños asentados en el NOA con sus ayllus de origen se pueden verificar en el pago del tributo realizado a través de sus caciques en el salar de Atacama (Hidalgo 1984). Esto nos plantea una relación a distancia que se mantendrá dinámicamente, ya sea a través de la arriería hacendal como de la arriería indígena, quizás sobreviviendo incluso al reordenamiento de los límites nacionales en la puna y el desierto de Atacama.

La frontera chileno-argentina que divide actualmente a la puna del desierto de Atacama data de fines del siglo XIX y principios del siglo XX. Esta delimitación internacional afectó al espacio de relaciones preexistentes de la población indígena, a los arrieros y a la arriería. Antes de la Guerra del Pacífico o del Salitre de 1879, la puna y la mitad del desierto de Atacama, desde la latitud de Paposo y hasta el río Loa, eran jurisdicción de la República de Bolivia. Los valles de Fiambalá, Santa María y Calchaquí y la quebrada del Toro eran jurisdicción argentina, y la mitad meridional del desierto de Atacama pertenecía a Chile. Luego, la puna y el desierto de Atacama quedaron repartidos entre Argentina y Chile, al perder Bolivia el desierto de Atacama y canjear con Argentina la puna a cambio de Tarija. Los nuevos límites y fronteras chileno-argentinos se demarcan entonces en virtud de los tratados de 1881 y de 1899 , resultando de su aplicación la separación del desierto de la puna de Atacama, y la fragmentación de los espacios sociales, económicos y ecológicos complementarios.

En el nuevo mapa de Atacama, el Estado argentino y el chileno se esmeran por controlar las fronteras y el tráfico de productos a través de la suscripción de tratados de libre comercio, de la habilitación de pasos fronterizos oficiales y de la creación en la década de 1920 y 1930 de cuerpos de policía de vigilancia fronteriza ${ }^{7}$. Sin embargo, se desentienden de las relaciones indígenas precedentes en estos territorios, y como señalan Delgado y Göbel (2003) las nuevas fronteras fragmentaron el territorio y alteraron las relaciones culturales y económicas indígenas entre la puna y el desierto de Atacama.

En el caso de la arriería hacendal, el aumento del tráfico de ganado e incremento de remesas coincidió con el establecimiento de la nueva frontera y con el auge salitrero y minero en el desierto de Atacama y la región de Tarapacá. "De 15.376 animales arriados en 1910, se pasa a casi 30 mil en 1913, contabilizados en las aduanas argentinas de Cachi y Salta, pasando por esta última más del 90\% del ganado con destino a Chile" (Conti 2003:37) ${ }^{8}$. La 
ruta ganadera salía de Rosario de Lerma, donde se emprendía el cruce de la cordillera por Huaytiquina y se bajaba a San Pedro de Atacama. Los arreos, cada uno de 100 animales, se efectuaban durante los meses de mayo a septiembre (Denis 1920). Otros pasos secundarios fueron Losló, Puntas Negras, Incahuasi y Socompa, que actuaban como bisagras de articulación fronteriza. Para algunos autores, esta arriería habría expirado en la década de 1930 cuando sobreviene la crisis económica del salitre (Conti 2003). Otros sitúan su extinción al momento de construirse el ferrocarril de Antofagasta a Salta en 1945 (Benedetti 2005a), aunque Del Valle y Parrón (2006) aportan cifras de exportación de vacunos al norte de Chile hasta el año 1954, algunas realizadas por ferrocarril. Ocurre entonces que la arriería hacendal expira a mediados del siglo XX.

\section{Los Otros Arrieros: Articulaciones Transfronterizas}

El trabajo etnográfico realizado en la puna y valles de Catamarca, en la cordillera de Copiapó y en los poblados meridionales del salar de Atacama entre 2000 y 2009, ha permitido relevar las articulaciones transfronterizas de la arriería indígena, desarrollada desde inicios del siglo XX, hasta años recientes. Antofagasta de la Sierra, Antofalla y Fiambalá, en la puna de Catamarca, Peine y Socaire en el salar de Atacama, las quebradas del Chaco y Sandón en la zona central del desierto, y Pedernales, Potrerillos y Quebrada de Paipote, en la cordillera de Copiapó, estas últimas ocupadas por migraciones collas arribadas desde el noroeste argentino desde fines del siglo XIX (Garrido 2000; Molina 2004), muestran que entre estas localidades se constituyó una red de intercambios y relaciones sociales transfronterizas, articulada por los otros arrieros ${ }^{9}$.

Los relatos personales se remontan hasta la década de 1930 y los relativos a segundas personas o familiares, hasta inicios de 1900. Éstos dan cuenta de las características y dinámicas del intercambio transfronterizo, de los ritmos de auge o decaimiento de esta actividad a lo largo del siglo XX y los primeros años de la presente centuria. En las narraciones se da cuenta de una importante movilidad entre el salar y la puna de Atacama, la que se suspende en septiembre de 1973 y se restablece tímidamente en la década de 1980 (Molina 2007). En los relatos de viajes referidos a la arriería e intercambio entre el valle de Fiambalá y la cordillera de Copiapó ocurre esta misma reducción de la movilidad transfronteriza desde mediados de la década de 1970, aunque la regularidad de los viajes aparece restableciéndose en la década de 1990, una vez que se retiraron los puestos militares de la puna de Copiapó -Laguna del Negro Francisco y en sector Pedernales-, continuando esta actividad hasta hace unos años. Estos viajes transfronterizos contradicen las aseveraciones que sostienen que la arriería indígena de la puna meridional hacia el desierto de Atacama habría terminado durante el siglo XIX (García et al. 2002), y de aquellos que sitúan su desaparición a mediados del siglo XX (Bolsi 1968; Benedetti 2005b; Cipolletti 1984). Más bien, los viajes relatados continúan y complementan los estudios realizados por Göbel (1998) y Rabey et al. (1986) en la Puna de Jujuy sobre movilidad e intercambio más allá de las fronteras.

Las actividades de intercambio se realizaban de modo discreto, pues los otros arrieros tenían conciencia que era una actividad considerada contrabando en Chile y Argentina, penada por el ordenamiento legal de cada país. Pese a ello, los viajes transfronterizos ocurrieron prácticamente durante la mayor parte del siglo XX. En éstos, el conocimiento de la geografía y de las rutas actúan como aliados en la articulación entre los asentamientos indígenas más próximos a la frontera de ambos lados de la cordillera. La existencia y creación de lazos de amistad, compadrazgo y parentesco entre estas localidades favorecieron el intercambio, pues fueron el soporte de una red social que contribuía a reducir el riesgo de la transgresión de los límites $\mathrm{y}$ fronteras de los estados nacionales, teniendo siempre el arriero un seguro puerto de arribo, donde contaba con la discreción de la comunidad durante su permanencia.

La arriería indígena, de collas y atacameños, como se nombran o se autoidentifican las familias de la puna meridional y del desierto de Atacama, se ha caracterizado por la movilidad de ganado propio, -principalmente mulares, burros, caballos, ovejas y corderos- o adquirido por la compra y venta, el trueque o el intercambio. Además, esta arriería considera el intercambio de productos agrícolas cosechados o elaborados en sus poblados de origen -uvas, pasas, maíz, papas, higos secos, trigo, harina, quínoa, vino y aguardiente-, productos pecuarios -quesos, charqui y cueros curtidos-, textiles -lana hilada, ponchos, puyos, frazadas, peleros, alforjas, guantes, bufandas, medias y escarpines-, bienes 
de consumo comprados o intercambiados -hojas de coca en medidas de tambo y cesto-, productos farmacéuticos y manufacturados -crema Lechuga, salicilato de metilo, grasa, clavos de herrar y herraduras, telas y ropa usada, zapatos, máquinas de coser, máquinas de escribir, neumáticos o gomas, radiotransistores, grabadoras y otros bienes diversos. Todos éstos se incorporaron al flujo de intercambio y complementaron las economías familiares y locales ubicadas en diversas zonas ecológicas del desierto y la puna de Atacama y el valle de Fiambalá. Los otros arrieros crearon entonces un mercado "externo" -constituido por las localidades transfronterizas- para los productos locales y para la obtención de otros bienes escasos y preciados en sus lugares de origen.

Las transacciones de productos y animales se efectuaban preferentemente mediante el trueque, siendo marginal el uso de moneda ${ }^{10}$. La vía de "capitalización" de los otros arrieros es el incremento de los valores de cambio de los productos ofrecidos y obtenidos en el trueque transfronterizo. Similar beneficio obtenía quien en su localidad hacía el intercambio, al conseguir productos con valor de uso o de cambio que eran difíciles de adquirir a nivel local, por su inexistencia o alto precio. Entonces era muy beneficioso intercambiar, a uno u otro lado de la cordillera, animales por bienes manufacturados y también a la inversa. Lo era además 'cambalachear' animales por textiles de lana, o adquirir productos agrícolas complementarios para la subsistencia y consumo que diversificaban la dieta. Estos intercambios transfronterizos permitieron a las economías indígenas del valle de Fiambalá y la puna de Catamarca acceder a productos agrícolas, hojas de coca, animales -burros y mulas, algunos provenientes de la cordillera de Copiapó-, y productos manufacturados e industriales, que se encontraban y todavía se encuentran fuera del alcance monetario de la economía familiar indígena, pero que sí son accesibles por el trueque. A su vez, para los arrieros indígenas del desierto de Atacama la obtención de remesas de animales y artesanía de lana, generalmente cambiadas por productos manufacturados, hojas de coca y en algún tiempo pasado por cueros de vicuñas y guanacos, les reportaban convenientes ganancias e incremento de los bienes de subsistencia.

La iniciativa y dirección del viaje de intercambio transfronterizo muchas veces estuvo regulada por el valor que adquirían los productos en el intercambio.
Los testimonios señalan que hasta mediados de la década de 1960, la iniciativa de la arriería fue preferentemente desde los valles y la puna meridional del NOA hacia Copiapó y el salar de Atacama. Después, y hasta 1973, la arriería se impulsó principalmente desde el salar de Atacama y Copiapó hacia la puna y los valles del NOA. Luego, los otros arrieros enfrentaron dos hechos que interrumpieron o desincentivaron el intercambio: la ocupación militar de la cordillera en Copiapó a partir de 1973 y la amenaza del conflicto argentino-chileno de 1978, que cerraron temporalmente la frontera binacional e inhibieron o dificultaron los desplazamientos de los otros arrieros, los que se reanudaron con mayor regularidad a partir de la década de 1980, hasta recientes años (Molina 2010).

\section{EI Viaje Transfronterizo}

En la preparación y desarrollo del viaje de los otros arrieros están involucradas las expectativas económicas -tipos de productos a intercambiar y adquisición de nuevos valores de cambio y de uso- y las variables relativas al desplazamiento -peligros y riesgos, tiempos y rutas a utilizar-. La buena conjugación de éstas aseguraba el éxito de las relaciones transfronterizas o, de lo contrario, se arriesgaba la pérdida de los bienes y el capital de modo irreversible, así como la libertad temporal.

En muchos casos, el viaje se preparaba teniendo en cuenta los compromisos adquiridos en la temporada anterior, en la que se acordaba "la vuelta", o bien se iniciaba por decisión propia. El viaje de los arrieros podía ser solitario, con un ayudante o con dos o tres peones "enganchados", o estar constituido por amigos, familiares, conocidos o arrieros de ocasión. En estas empresas existía a veces un patrón dueño del ganado o del negocio e intercambio. Cuando el número de animales transportados era considerable se distinguía una organización que se componía de: el 'patrón' o dueño del arreo, un 'baquiano' que podía ser el mismo "patrón", el que conocía el camino -y se disponía siempre ubicado unos kilómetros delante de los animales -ovejas, burros y mulas-, previendo el peligro-. Junto al ganado o la hacienda iban el 'marucho' o 'madrinero', que conducía la mula o yegua madrina, y los 'peones' que agrupaban los animales arreados. Pero en la mayoría de los viajes de arreo e intercambio la partida estaba formada por uno o dos hombres. 
Los viajes con burros y mulas se realizaban en todo tiempo, muchos de éstos en invierno, cuando los arrieros estaban desocupados de otros quehaceres de la economía familiar -especialmente cosechas y término de la engorda del ganado-, periodo que coincidía con la disminución de la vigilancia fronteriza. Los viajes con arreo de ovejas, en general, se realizaban en los meses de abril y mayo, cuando estaban mejor alimentadas y los corderos tenían varios meses de edad. Estos se 'ojeteaban' -se les colocaba una protección de cuero en las patas- para evitar la 'despiedadura' o daño de las pezuñas provocado por las piedras y los terrenos salitrosos que se encontraban en el camino. Otros viajes coincidían con los meses de postcosecha para realizar el 'cambalache', pues en dichas épocas había disponibilidad de dinero para comprar bienes para el intercambio. Todos estos factores constituían la oportunidad y, a la vez, la complejidad del viaje de arreo e intercambio transfronterizo.

Las rutas utilizadas eran los 'caminos de herradura' tradicionales y otros desconocidos, evitando aduanas y puestos de control policial. Los pasos utilizados preferentemente por estos arrieros eran Incahuasi-Pular, Socompa (al norte del volcán), Aguas Calientes (al sur del Llullaillaco), La Azufrera-Salar de Gorbea, Plato de Sopa, Leoncito, Laguna Brava-Los Colorados, San Francisco y Tres Quebradas, todos ubicados sobre los $4.000 \mathrm{msm}$. Estos permitían, a lo largo de la frontera, articular las distintas áreas de la puna y valles de Catamarca con el desierto de Atacama (Figura 1).

En los viajes reportados entre 1940 y 1970 , los otros arrieros señalan que los puestos de la Gendarmería argentina se ubicaban cerca de la vega de Caipe, Tolar Grande, San Antonio de Los Cobres y Fiambalá. Los retenes de los Carabineros de Chile se localizaban en los faldeos del volcán Socompa, cerca del paso de San Francisco y en Potrerillos, pero en las localidades de Peine, Socaire, Pedernales, Doña Inés, las aguadas del desierto y otras zonas de la cordillera no existían estos destacamentos. Cuando en la ruta de arriería había puestos de vigilancia, se esperaban las horas de mayor oscuridad y frío para vadearlos pasando lejos con los animales, continuando el camino hasta quedar fuera del alcance de la policía. Cuando tomaban rutas alternativas, disminuía el peligro de sufrir la confiscación de los animales, de la carga, y la detención, salvándose de procesos judiciales por contrabando e ingreso ilegal al país, tanto en Chile como en Argentina.
Además, los arrieros afrontaban en sus viajes las amenazas derivadas del clima de estas regiones, las nevadas de invierno y verano en la puna meridional, el viento 'sonda' en las quebradas y los valles, las ventiscas de arena, el temido viento blanco de la cordillera y el intenso frío del invierno. En el desierto de Atacama, los peligros tenían relación con el frío y la disponibilidad de agua, leña y pastos en el camino.

Durante la década de 1970 se agudizaron las restricciones para el desplazamiento transfronterizo, debido a factores políticos y de beligerancia internacional, lo que provocó la disminución del tráfico de los arrieros collas y atacameños. En el caso de la arriería de Copiapó con el valle de Fiambalá y con la puna meridional de Atacama, ésta prácticamente desapareció con el Golpe de Estado de 1973 en Chile, cuando la cordillera de los Andes fue ocupada por los militares. Años después, en 1978, ocurre el conato de conflicto binacional por el diferendo austral, aumentando la vigilancia y control fronterizo, instalándose campos minados por ambos lados de la frontera, coincidiendo la implantación de los explosivos con la mayoría de las rutas utilizadas por los otros arrieros, afectando el tráfico de la arriería indígena entre el salar de Atacama y la puna meridional del $\mathrm{NOA}^{11}$.

Superado el conato de conflicto binacional, los espacios fronterizos fueron objeto de activas políticas de integración territorial, de inversión social y en infraestructura vial en Chile y Argentina, que favorecieron el acceso y abastecimiento de productos manufacturados a las localidades aisladas (Jiménez y Pessina 1993). A esta mayor presencia del Estado, incluyendo la creación de municipios locales, se sumó en algunas zonas la inversión de capitales para la explotación de recursos minerales, lo que incrementó la asalarización de la población indígena, impactando sobre la regularidad y objetivos de los viajes transfronterizos. Aun así, en las décadas del ochenta y noventa del siglo XX los arrieros indígenas habían restablecido tímidamente estos viajes, readecuando las rutas o vadeando los campos minados de la frontera. Los últimos arreos conocidos se efectuaron hasta el primer lustro del siglo XXI, siendo el trayecto entre el salar de Atacama y la zona de Antofagasta de la Sierra y entre el valle de Fiambalá y la cordillera de Copiapó. En éstos, el intercambio general fue el trueque de animales -mulas, burros y ovejas-, textiles, hojas de coca, bienes manufacturados y tecnológicos. 


\section{Consideraciones Finales}

Los otros arrieros de los valles y la puna meridional del NOA y del desierto de Atacama han sido parte de una realidad desconocida, cuyas prácticas de articulación transfronteriza superan en el tiempo a la actividad realizada por la arriería hacendal. Esta arriería de adscripción étnica colla y atacameña ha utilizado estrategias de intercambio a distancia, con anclajes sociales y territoriales más allá de las fronteras, favoreciendo la complementación de productos de las economías indígenas, y de algún modo sobrevivió hasta recientes años, sustentada en lazos y redes de parentesco, compadrazgo y amistad (Göbel 2009; Molina 2010).

Para los Estados nacionales chileno y argentino esta arriería es contrabando y los arrieros migrantes ilegales. La persecución y sanción de estas formas tradicionales de contacto transfronterizo, que preceden a la presencia de estos Estados, ha sido el modo de relacionarse con los otros arrieros, que al ser detectados se les ha detenido, confiscado los bienes, eliminado el ganado y procesado judicialmente, hechos que han contribuido a inhibir el intercambio transfronterizo. Estos procedimientos son atribuibles a las políticas económicas de los Estados vecinos, que han privilegiado la exportación de productos a los mercados internacionales, aumentando las barreras sanitarias y el control de las fronteras. De allí que estos arrieros libres se transforman en una amenaza, al estar fuera del control de la burocracia y la policía y de la mirada de los Estados.

Los Estados de Chile y Argentina, desde 1990 se han ocupado de la integración, firmando tratados mineros, de cooperación técnica y científica, de comercio, de turismo y energéticos, pero han soslayado la presencia e integración de las comunidades indígenas, tal como se hizo con los tratados de límites internacionales de fines del siglo XIX. La otra arriería, a pesar de los cambios ocurridos en las últimas décadas, relacionados con la integración territorial nacional y la mayor presencia del Estado en estos territorios, muy probablemente siga existiendo, recorriendo en silencio las inmensidades de la puna y el desierto, adquiriendo estas prácticas tradicionales un nuevo signo o una nueva estrategia de articulación. Su valor ha residido en la contribución del intercambio bajo patrones andinos para mejorar las formas de subsistencia económica y cultural de collas y atacameños, articulando una red social y conectando territorios histórica y culturalmente complementarios, como la puna y el desierto de Atacama, separados arbitrariamente por las fronteras de los Estados nacionales.

Agradecimientos: Este trabajo forma parte de los resultados del proyecto Fondecyt No 1040290. Mis agradecimientos al trabajo de los evaluadores que contribuyeron con sus observaciones a potenciar los contenidos y a mejorar la discusión de las ideas expresadas en este artículo.

\section{Referencias Citadas}

Aranda, $\mathrm{X}$

1969 Evolución de la agricultura y el riego en el Norte Chico: Valle del Huasco. Informaciones Geográficas. Número Único 1966:9-41. Departamento de Geografía. Universidad de Chile, Santiago.

Bhabha, H.K.

2000 Narrando la Nación. En La Invención de la Nación. Lecturas de la Identidad de Herder a Homi Bhabha, compilado por Á. Fernández B., 211-219. Manantial, Buenos Aires.

Benedetti, A.

2005a El ferrocarril Huaytiquina, entre el progreso y el fracaso. Aproximaciones desde la geografía histórica del Territorio de Los Andes. Revista de la Escuela de Historia I (4):123-165. Edición digital: http://www.unsa.edu.ar/ histocat/revista/revista04.htm

2005b Un Territorio Andino para un País Pampeano; Geografía Histórica del Territorio de Los Andes (1900-1943). Tesis Doctoral. Facultad de Filosofía y Letras, Universidad de Buenos Aires, Buenos Aires.
Bertrand, A 1885 Memoria sobre las Cordilleras de Atacama i Regiones Limítrofes. Imprenta Nacional, Santiago.

Bolsi, A.

1968 La región de la Puna Argentina. Revista de la Facultad de Filosofía y Letras 10:75-129. Universidad Nacional del Nordeste, Resistencia, Chaco.

Cipolletti, M.S

1984 Llamas y mulas, trueque y venta: El testimonio de un arriero puneño. Revista Andina 2:513-538.

Castro, N., J. Hidalgo y V. Briones

2002 Fiestas, borracheras y rebeliones (Introducción y transcripción del expediente de averiguación del tumulto acaecido en Ingaguasi, 1777). Estudios Atacameños 23:77-109.

Conti, V.

2003 El norte argentino y Atacama. Flujos mercantiles, producción y mercados en el siglo XIX. En Puna de Atacama. Sociedad, Economía y Frontera, compilado por A. Benedetti, pp. 21-52. Alción Editora, Córdoba. 
2006 La Ruta de los Arrieros y el Salitre. En Las Rutas del Capricornio Andino: Huellas Milenarias de Antofagasta, San Pedro de Atacama, Jujuy y Salta, pp. 93-104, Consejo de Monumentos Nacionales, Santiago.

Conti, V. y G. Sica

2007 Arrieros y arrieraje de la región circumpuneña en la larga duración. Ponencia presentada en el $1^{\text {er }}$ Congreso Latinoamericano de Historia Económica, Simposio: 24. Participación indígena y campesina en los circuitos mercantiles rurales y urbanos. América Latina, siglos XVIII y $X I X$. CLADHE, Montevideo.

Contreras, $\mathrm{R}$

2005 Pueblos Transfronterizos en la Puna de Atacama: Conectividad de Redes en el País más allá de las Nubes. Memoria para optar al título profesional de Antropólogo Social. Departamento de Antropología, Facultad de Ciencias Sociales, Universidad de Chile, Santiago.

De la Orden, G. y J.L. Parodi

2005 Los desnaturalizados calchaquíes en el Valle central de Catamarca a fines del siglo XVII. Actas del VI Congreso Internacional de Etnohistoria. 22 al 25 de noviembre de 2005. Edición digital (CD), Buenos Aires.

Del Valle, A. y G. Parrón

2006 La Región de los Nortes; Salta y el comercio de ganado vacuno con Chile. "Ilusiones y Desencantos" del Ferrocarril Huaytiquina (1946-1955). Estudios Transandinos 13: 29-53, Revista de la Asociación Chileno-Argentino de Estudios Históricos e Integración Cultural, San Juan.

Delgado F. y B. Göbel

2003 Departamento de Susques: La Historia Olvidada de la Puna de Atacama. En Puna de Atacama: Sociedad, Economía y Frontera, compilado por A. Benedetti, pp. 81-103. Alción Editora, Córdoba.

Denis, $\mathrm{P}$.

1987 [1920] La Valoración del País. La República Argentina. Ediciones Solar, Buenos Aires.

García, S., D. Rolandi, M. López y P. Valeri

2002 Viajes comerciales de intercambio en el departamento de Antofagasta de la Sierra, Puna meridional argentina: pasado y presente. Redes-Revista Hispana para el Análisis de Redes Sociales 2(5), mayo http://revista-redes.rediris.es

García, S. y P. Valeri

2007 Antofagasta de la Sierra: de Chile a Catamarca. Los vínculos comerciales y de parentesco en la memoria oral y en los archivos. VII Congreso Argentino Chileno de Estudios Históricos e Integración Cultural. Universidad de Salta, Salta. Edición digital.

Garrido, C.

2000 Informe Antropológico, Comunidad Colla Potrerillos. Informe Final del proyecto Conadi: Acciones de Apoyo para el Traspaso de Predios o Inmuebles Fiscales a Favor de Comunidades, Asociaciones, Familiares y otras Organizaciones Indígenas de la III Región de la Comunidad Indígena Colla de la Comuna de Diego de Almagro. Consultora INAS-Conadi Norte. Manuscrito en posesión del autor.

Gil M., R.

2004 Caravaneros y Trashumantes en los Andes Meridionales. Población y Familia Indígena en la Puna de Jujuy, Serie Historia Andina 28. Instituto de Estudios Peruanos, Lima.

Göbel, B

1998 "Salir de Viaje": Producción Pastoril e Intercambio Económico en el Noroeste Argentino. En 100 Años de
Estudios Americanistas de la Universidad de Bonn. Nuevas Contribuciones a la Arqueología, la Etnohistoria, Etnolingüística y Etnografía de las América, editado por S. Dedenbach-Salazar Sáenz, C. Arellano Hoffmann, E. König y H. Prümers, pp. 867-891. Bonner Amerikanistische Studien 30. Markt Schwaben: Verlag Anton Saurwein. 2003 "La Plata no Aumenta, la Hacienda sí”: Continuidades y Cambios en la Economía Pastoril de Susques (Puna de Atacama). En Puna de Atacama: Sociedad, Economía y Frontera, compilado por A. Benedetti , pp. 199-241. Alción Editora, Córdoba.

2009 "Conviene bastante tener un amigo"; Interés económico y significados culturales en los Andes. Revista Humboldt 151:39.

Guber, R.

2005 La Etnografía; Método, Campo y Reflexividad. Grupo Editorial Norma, Bogotá, Colombia.

Guerrero, A. y T. Platt

2000 Proyecto antiguo, nuevas preguntas: La antropología histórica de las comunidades andinas cara al nuevo siglo. Cuadernos 8:95-113 (Estado-Nación, Comunidad Indígena, Industria: Tres Debates al Final de Milenio), AHILA, Ridderprint, Ridderkerk, Holanda.

Hammersley, M. y P. Atkinson

1994 Etnografía: Métodos de Investigación. Ediciones Paidós, Barcelona.

Hidalgo, J.

1984 Complementariedad ecológica y tributo en Atacama: 1863-1792. Estudios Atacameños 7:422-442.

Jiménez, D. y L. Pessina

1993 El impacto de la ruptura del aislamiento en una población de pastores de altura. En Estudios Socio-Antropológicos de la Puna Catamarqueña, editado por F. Forni, M.I. Tort, D. Jiménez y L. Pessina CEIL-PIETTE, Centro de Estudios de Investigaciones Laborales, CONICET, Buenos Aires. http://bibliotecavirtual.clacso.org.ar/ar/libros/argentina/ ceil/forni.rtf

Lera, M.E.

2007 Los arrieros del valle Calchaquí en los circuitos mercantiles a fines del siglo XIX. El caso de Cachi. VII Congreso Argentino Chileno de Estudios Históricos e Integración Cultural, Universidad de Salta, Salta. Edición digital.

Lorandi, A.M.

1988 La resistencia y rebeliones de los diaguita-calchaquí en los siglos XVI y XVII. Cuadernos de Historia 8:99-122, Departamento de Ciencias Históricas, Universidad de Chile, Santiago.

Martínez, J.L.

1998 Pueblos del Chañar y El Algarrobo: Los Atacamas en el Siglo XVII. Ediciones de la Dirección de Bibliotecas y Museos. Colección Antropología, Santiago.

Meister, A., S. Petruzzi y E. Sonzogni

1963 Tradicionalismo y Cambio social. Estudio de Área en el Valle de Santa María. Publicación 1, Facultad de Filosofía y Letras, Universidad Nacional Laboral, Rosario.

Molina, R.

2004 Los collas de la cordillera de Atacama. En La Memoria Olvidada: Historia de los Pueblos Indígenas de Chile, compilado por J. Bengoa, pp. 213-245. Cuadernos Bicentenario, Presidencia de la República, Santiago.

2007 Viajes, arriería, intercambios y articulaciones, entre la Puna y el desierto de Atacama: Relatos desde Antofagasta 
de la Sierra, Antofalla, Fiambalá y Copiapó. VII Congreso Argentino Chileno de Estudios Históricos e Integración Cultural. Universidad de Salta, Salta. Edición digital.

2010 Collas y Atacameños en el Desierto y la Puna de Atacama y Valle de Fiambalá: Sus Relaciones Transfronterizas. Tesis Doctoral en Antropología. Universidad de TarapacáUniversidad Católica del Norte, Arica-Antofagasta.

Núñez, L.

1992 Cultura y Conflicto en los Oasis de San Pedro de Atacama. Editorial Universitaria, Santiago.

Philippi, R.

1860 Viage al Desierto de Atacama (Hecho por orden del Gobierno de Chile en el Verano de 1853-54). Librería de Eduardo Antón, Santiago.

Platt, T.

1987 Calendario tributario e intervención mercantil: Racionalidades estacionales entre los indios de Lípez (Bolivia) en el siglo XIX. Chungara 19:215-241.

Rabey, M., R. Merlino y D. González

1986 Trueque, articulación económica y racionalidad campesina en el sur de los Andes Centrales. Revista Andina 4:131-160.

Rodríguez, L.

2004 Migraciones en los Andes Meridionales. El caso de los atacameños en Santa María durante la segunda mitad del siglo XVIII. Revista Andina 39:103-124.
Sanhueza, C.

1991 Orígenes y Desarrollo de la Arriería Indígena Colonial en Atacama. Siglos XVI y XVII. Tesis para optar al Grado de Licenciado en Historia, Pontificia Universidad Católica, Santiago.

2001 Las poblaciones de la Puna de Atacama y su relación con los Estados Nacionales. Una Lectura desde el Archivo. Historia Indígena 5:55-82, Departamento de Ciencias Sociales, Universidad de Chile, Santiago.

Santamaría, D.

1996 Intercambios comerciales internos en el Alto Perú colonial tardío. Revista Complutense de Historia de América 22:239-273, Centro de Estudios Indígenas y Coloniales, Universidad de Jujuy y Universidad Complutense de Madrid, Madrid.

Sayago, J.M.

1997 [1874] Historia de Copiapó. Editorial Francisco de Aguirre, Santiago.

Tarragó, M.

1984 La historia de los pueblos circumpuneños en relación con el altiplano y los Andes Meridionales. Estudios Atacameños 7:116-131.

Von Tschudi, J.J.

1966 Viaje por las Cordilleras de los Andes de Sudamérica, de Córdoba a Cobija, en el año 1858. Boletín de la Academia Nacional de Ciencias, Tomo 45, Córdoba.

\section{Notas}

1 Conti (2003:43) comenta: "No esta de más recordar que existía un importante ocultamiento de volúmenes -del orden del 50\% del total de las exportaciones-, ya que la mayor parte del tráfico se realizaba por boquetes de la cordillera que evitaban los resguardos aduaneros".

2 Cipolletti (1984) y García y Valeri (2007) realizan una etnografía de la movilidad de los arrieros y llameros entre los valles, la puna y el salar de Atacama y el altiplano de Lípez y Tarija en Bolivia. Describen en ellos los intercambios, el trueque y el 'cambalache' y las relaciones interétnicas. Rabey et al. (1986) hace lo propio para la misma zona de la puna de Salta y Jujuy y da ejemplos de relaciones de arriería transfronteriza entre Chile y Argentina, que operaban hasta 1984.

3 Testimonio de don Catalino Soriano Mamani. Sector La Tranca, Vega del río Punilla, Antofagasta de la Sierra, 30 de enero de 2006.

4 En San Pedro de Atacama, a mediados del siglo XIX, un tercio de sus habitantes estaban dedicados al transporte de mercaderías de Cobija a las provincias argentinas de Salta, Jujuy y Tarija (Philippi 1856), y en el siglo XX, allí se reponían y engordaban los animales que iban de Salta con destino a las salitreras (Conti 2003). El valle Calchaquí contaba con mano de obra especializada en las tareas de cuidado y amanse, cultivo de forrajeras y mantenían el oficio de la arriería (Conti y Sica 2007). Lera (2007) menciona que los arrieros de la Quebrada El Toro llevan la hacienda con destino al desierto de Atacama, en cambio, los arrieros de Payogasta, durante el siglo XIX, llevan mulares y ganado hacia Bolivia.
5 En 1979, dos arrieros de Peine, Hilario y Adrián Plaza, fueron detenidos con sus "cargas" por la Gendarmería argentina en las inmediaciones de Antofagasta de la Sierra (Omar Ramos, Antofalla, comunicación personal, abril de 2008). Se les siguió juicio en Catamarca, donde se les mantuvo retenidos (Héctor Reales, Fiambalá, comunicación personal, abril de 2008). Contreras (2005) consigna que el Servicio Agrícola y Ganadero SAG y Carabineros de Chile, en agosto de 2003, quemaron los animales y la carga de una caravana tradicional proveniente de Quetena (Bolivia), destinada al intercambio de los productos puneños por los sampedrinos. En el mismo año 2003 arribaron a Toconao arrieros de Susques para 'cambalachear', pero fueron detenidos por Carabineros, confiscados sus bienes, sacrificadas las llamas e incinerados sus cuerpos. Los arrieros fueron encarcelados en Antofagasta (Viviana Conti, comunicación personal, 2007). La liberación fue lograda por las gestiones de la etnóloga Bárbara Göbel ante agencias de las Naciones Unidas (Contreras 2005).

6 Göbel (1998) en su trabajo acerca del viaje de los caravaneros del sector de Susques realiza una descripción etnográfica detallando cómo la población participa de estas caravanas y los aportes de animales y productos para el trueque.

7 El Cuerpo de Carabineros se fundó en Chile en 1927 y sus funciones fronterizas corresponden a la vigilancia y seguridad interna, evitar el tráfico de drogas, el contrabando de mercancías e ingreso ilegal de personas. La Gendarmería Nacional de Argentina se creó en 1938 y su misión legal (Ley 12.367) es "contribuir debidamente a mantener la identidad nacional en las áreas limítrofes, 
preservar el territorio nacional y la intangibilidad del límite internacional".

8 Por ejemplo, en el año 1910 salieron por Salta 15.126 vacunos y por Cachi 250 animales, lo que hace una exportación total de la provincia de 15.376 cabezas de ganado vacuno. Sin embargo, las cifras serían aún mayores puesto que "Según el informe Consular de 1912, en 1910 entraron a Chile 31.000 bovinos, los cuales se comercializaron de la siguiente manera; 13.440 fueron a Antofagasta; 3.000 a Boquete, Calama y Oficina Cecilia; 3.240 a Tarapacá; 8.520 a Tocopilla, Collahuasi y Chuquicamata, y 2.760 fueron a Taltal" (Conti 2003:37-41).

9 Los antecedentes expuestos han sido sistematizados de las entrevistas sostenidas con las siguientes personas: En el desierto de Atacama, en Chile, Don Esteban Ramos y Don Jesús Escalante, de Potrerillos. Don Paulino Bordones, Don Marcos Bordones y Doña Paulina Segura, de Quebrada Paipote. Don Osvaldo Jesús Maldonado, de Taltal. En Argentina, Doña Tomasa Reales y Adán Reales, de Fiambalá, Don Felipe Salva y Don Seferino Fabián, de Antofalla, Don Antonio Alancay, de Las Quínoas de Antofalla, Don Catalino Soriano Mamani, Don Vicente Fabián y Don Eusebio Vásquez, de Antofagasta de la Sierra.
10 Este intercambio ha operado de modo distinto en otras áreas puneñas, como Lípez en el siglo XIX, donde los arrieros combinan asalarización, trueque y mercado (Platt 1987), o diferente de las etapas de la arriería de Susques dichas por Göbel (2003), una ocurrida hasta mediados del siglo XX basada en el intercambio caravanero -que podría asemejarse a la actividad de los otros arrieros en el uso preferente del trueque-, y otra posterior de surgimiento de economías monetarizadas ligadas a la venta de ganado. Más cercano a las características de los otros arrieros son los viajes de trueques de los caravaneros de llamas entre la puna de Jujuy y San Pedro de Atacama de la década de 1970, estudiado por Cipolletti (1984).

11 En la frontera del Departamento de los Andes (Salta) con el desierto de Atacama (Región de Antofagasta) se constató la existencia de campos minados en las inmediaciones de los cerros Aracar, Bayo y Tecar, la quebrada del Llullaillaco, la ladera sur del mismo volcán y los portales de Huaytiquina, Socompa y Aguas Calientes (Diario El Tribuno de Salta, 16 de agosto de 1999). Todos estos pasos minados corresponden en su mayoría a los derroteros y caminos utilizados por los arrieros. 